\title{
Microbes and plastic waste management
}

\author{
Samina Mehnaz ${ }^{1} \cdot$ Ayesha Javaid $^{1}$
}

Published online: 24 November 2020

(c) Society for Environmental Sustainability 2020

Environmentalists around the globe are concerned about emission of greenhouse gases, depletion of ozone, synthetic and non-degradable chemicals-produced by the industry in the form of fertilizers, pesticides, plastics, polymers, etc. Microbes are involved in many processes that help in improving the environment; bacteria, fungi, protozoa, bacteriophages and even nematodes are responsible for environmental sustainability as they contribute in several ways in the ecosystems. Removal of heavy metals from ground water and soil, increasing soil fertility, nitrogen fixation, nutrients solubilization, eating bad microbes, degrading the plastic, producing the biodegradable plastic; just to name some mechanisms these organisms use for improving the environment.

Polyethylene (PE) and polypropylene (PP) represent $\sim 92 \%$ of plastic production. Degradation of synthetic plastic is a global issue affecting almost every ecosystem on earth. It takes years to get plastics degraded by natural mechanisms as microbes take long to understand the nature of compounds used in these recalcitrant products. Possible solution to tackle this menace is to discover the microbes that can degrade plastics and enhance their ability to do so. Many organisms including bacteria and fungi are reported to degrade the synthetic plastics. Penicillium simplissimum was reported for modest degradation of plastic (Yamada-Onodera et al. 2001). Nocardia destiroides was reported for the degradation of PE (Bonhomme et al. 2003). Yoshida et al. (2016) reported faster biodegradation of Polyethylene terephthalate (PET) by a microbial consortium including a novel bacterium Idionella sakaiensis. A Pseudomonas strain isolated from soil of plastic dumping site was reported to grow on polyurethane oligomers and monomers (Cardenas Espinosa et al. 2020). Three years ago, caterpillar of wax moth Galleria mellonella was reported to degrade PE (Bombelli et al.

Samina Mehnaz

saminamehnaz@fccollege.edu.pk

1 School of Life Sciences, Forman Christian College (A

Chartered University), Lahore 54600, Pakistan
2017). However, a major breakthrough which can lead to large scale degradation of plastics is still awaited.

Environment friendly polymers could be the substitutes for recalcitrant synthetic plastics. Biodegradable plastics are now being developed by incorporating biopolymers into conventional plastics or by microbial fermentations. Biopolymers have excellent biodegradability, biocompatibility and varied applications. Currently, polyhydroxy alkanoates (PHAs), polylactic acid (PLA), and polybutylene adipate-coterephthalate (PBAT) are well-known biodegradable polyesters that are commercially available in the market (Kim et al. 2017). The PHAs are synthesized hydroxy-fatty-acids within the microbial cells and stored as lipid inclusions when carbon is in abundance and nitrogen, phosphorus, oxygen or sulfur are limited. They are readily degraded by the depolymerases present in the environmental microflora resulting in the formation of water and carbon dioxide.

There are different types of PHA based on the monomers; polyhydroxy valerate (PHV), polyhydroxy hexanoate (PHH), polyhydroxy octanoate (PHC) and polyhydroxy butyrate (PHB). Among all these types, polyhydroxy butyrate (PHB) is the most commonly occurring biopolymer and it is completely biodegradable. It is produced by bacteria as a lipid inclusion body under stress conditions, when the concentration of essential nutrients like nitrogen, potassium, phosphorus, sulfur, magnesium or oxygen is limited and carbon is present in excess. It acts as an energy backup for bacteria. The properties of this polymer are very similar to that of commonly used plastics like polypropylene. It has thermoplastic properties, non-toxic, produced from renewable material and completely biodegradable. It also has low permeability for water and gases like oxygen and carbon dioxide. All these properties make it an excellent choice to replace synthetic plastics that are usually made from petrochemical sources. One drawback for its use in a wide range of products is its brittle nature. This problem can be solved by using a copolymer of PHB with polyhydroxy valerate (PHV). Adding PHV greatly improves the strength and flexibility of this biopolymer (Marchessault and Yu 2004). 
More than ninety hydroxy alkanoic acids have been reported as constituents of PHAs and among these, polyhydroxy butyrate (PHB) is synthesized by different microbes. Till date, at least 75 genera of bacteria have been discovered which produce PHB. These include Gram positive and Gram negative halophytic, photosynthetic and hydrocarbondegrading bacteria. All these bacteria have been isolated from diverse habitats with different environmental conditions, like terrestrial, freshwater, marine and waste streams from industries like oil, starch and paper. Most common of these are Pseudomonas, Archea, Actinobacter, Burkholderia and Azotobacter. PHB producing bacteria reside in variety of ecosystems where there is an imbalance in the available nutrients. Bacteria from other genera such as Bacillus, Staphylococcus, Paracoccus, Micrococcus, Rhodococcus, Methylobacterium, and Vibrio are also reported for PHB production. Few years ago, a strain of Cupriavidus $\mathrm{sp}$. isolated from wastewater from the cassava starch manufacturing industry, was reported to produce PHB (Poomipuk et al. 2014). The species of Bacillus, Alcaligenes and Pseudomonas, accumulate PHB up to $90 \%$ of cell dry weight under nutrients limited conditions (Prabisha et al. 2015). Recently, Pseudodonghicola xiamenensis, an isolate from Red Sea, has been reported for PHB production (Mostafa et al. 2020).

PHB has the potential to be utilized in a variety of products. It can be used to prepare water bottles, disposable cups, cutlery for fast food restaurants, lamination foils, female hygiene products and diapers. It is a safe choice to be used for the packaging of edible items. It can be utilized in medicine and agriculture owing to its non-toxic nature, biocompatibility and biodegradability. It is ideal to be used as a covering for capsules, for the controlled release of medicines, for stitching of wounds, bone implants, pacemaker, cardiovascular patches and nerve guides, etc. Similarly, it can be used for the slow release of fertilizers, insecticides, pesticides or fungicides in the soil.

Use of eco-friendly PHB in place of artificial plastics can improve the waste disposal problems and reduce greenhouse gas emissions. However, the high production cost imposes restrictions on the commercialization of PHB material. The carbon sources used for PHB-producing bacteria have been glucose, sucrose, dextrose, maltose and other types of sugars, and various types of oils which make the price of PHB at least four times higher than that of petroleum-based plastics. To solve this issue, scientists have started to look for other cheap alternate carbon sources. PHAs can be produced from sugars, agricultural wastes, glycerol and vegetable oil. Banana peel, corn cob, sugar cane bagasse and tuff straw have been used as substrates for Bacillus sp. (Getachew and Woldesenbet 2016). Soya, rice bran, wheat bran, sago starch and bagasse, have also been used as substrates for production of PHB (Shivakumar 2012). Wastes from the sugar industry, like molasses, fermented mash and spent wash, along with corn oil, have been used as substrates for Pseudomonas (Chaudry et al. 2011). Wastes from other types of industries such as pulp, paper and cardboard industry, wastewater, waste rapeseed oil, waste palm oil, oil extracted from the spent coffee grounds, wastewater from yeast industry and domestic waste water have also been explored for PHB production (Bhuwal et al. 2013; Cruz et al. 2014; Nogueira et al. 2018; Ozdemir and Ceyhan 2011; Verlinden et al. 2011). Recently, PHB production by Pseudodonghicola xiaminensis, is reported by using date syrup as a substrate (Mostafa et al. 2020). These studies support that agriculture wastes have the potential to be used as a substrate to generate PHB at a much lower cost than by using refined sugar sources.

Bioplastic industry is at its initial stage, however, it is growing and already has an emergent share in the global market. In 2017, more than 50\% bioplastic was produced in Asia. Japan is leading in bioplastic industry and using it in automobiles and electronic industry. USA and Latin America have also started investing in this industry. Similarly, in Europe, bioplastic market is expanding. Considering its use in diverse fields including medical, agriculture, electronics, etc., it is estimated that globally its demand will increase 19\% per year (Ojha and Kapoor 2019).

Microbes have solution of plastic waste management by degrading the synthetic plastic as well as replace it with degradable bioplastic. PHB's cost of production is a major hurdle. However, scientists are discovering new bacterial strains, developing recombinant strains, tailoring various forms of PHB, using variety of agriculture and industrial wastes as substrates, to reduce production costs. It is anticipated that global efforts in this area will soon make PHB available for its application in different areas and help in tackling one of the biggest issues of current times leading to sustainable development and conservation of biodiversity.

\section{References}

Bhuwal AK, Singh G, Aggarwal NK, Goyal V, Yadav A (2013) Isolation and screening of polyhydroxyalkanoates producing bacteria from pulp, paper, and cardboard industry wastes. Intern J Biomat 2013:1-10. https://doi.org/10.1155/2013/752821

Bombelli P, Howe CJ, Bertocchini F (2017) Polyethylene biodegradation by caterpillars of the wax moth Galleria mellonella. Curr Biol 27(8):R292-R293. https://doi.org/10.1016/j.cub.2017.02.060

Bonhomme S, Cuer A, Delort AM, Lemaire J, Sancelme M, Scott C (2003) Environmental biodegradation of polyethylene. Polym Degrad Stab 81:441-452

Cárdenas Espinosa MJ, Colina Blanco A, Schmidgall T, AtanasoffKardjalieff AK, Kappelmeyer U, Tischler D, Pieper DH, Heipieper HJ, Eberlein C (2020) Toward biorecycling: isolation of a soil bacterium that grows on a polyurethane oligomer and monomer. Front Microbiol 11:404 
Chaudhry WN, Jamil N, Ali I, Ayaz MH, Hasnain S (2011) Screening for polyhydroxyalkanoate (PHA)-producing bacterial strains and comparison of PHA production from various inexpensive carbon sources. Ann Microbiol 61(3):623-629. https://doi.org/10.1007/ s13213-010-0181-6

Cruz MV, Paiva A, Lisboa P, Freitas F, Alves VD, Simoes P, Barreiros S, Reis MAM (2014) Production of polyhydroxyalkanoates from spent coffee grounds oil obtained by supercritical fluid extraction technology. Bioresour Tech 157:360-363. https://doi. org/10.1016/j.biortech.2014.02.013

Getachew A, Woldesenbet F (2016) Production of biodegradable plastic by polyhydroxybutyrate (PHB) accumulating bacteria using low cost agricultural waste material. BMC Res Notes 9(1):1-9. https://doi.org/10.1186/s13104-016-2321

Kim MY, Kim C, Moon J, Heo J, Jung SP, Kim JR (2017) Polymer film-based screening and isolation of polylacticacid (PLA)degrading microorganisms. J Microbiol Biotechnol 27(2):342349. https://doi.org/10.4014/jmb.1610.10015

Marchessault RH, Yu G (2004) Crystallization and material properties of polyhydroxyalkanoates. In: Steinbuchel A (ed) Biopolymers. Wiley, New York, pp 157-248

Mostafa YS, Alrumman SA, Alamri SA, Otaif KA, Mostafa MS, Alfaify AM (2020) Bioplastic (poly-3-hydroxybutyrate) production by the marine bacterium Pseudodonghicola xiamenensis through date syrup valorization and structural assessment of the biopolymer. Nat Sci Rep 10:8815. https://doi.org/10.1038/s4159 8-020-65858-5

Nogueira R, Bhalerao A, Banerjee R (2018) Cost effective production of polyhydroxyalkanoate biopolymers using mixed microbial culture and industry wastewater: an ecofriendly approach. J Fundament Renew Energy Appl 8:64-65. https://doi. org/10.4172/2090-4541-C4-059

Ojha S, Kapoor S (2019) Bioplastics: the suitable and sustainable alternative to polyethylene plastics. Acta Sci Microbiol 2(6):145-148

Ozdemir G, Ceyhan N (2011) Poly-beta-hydroxybutyrate (PHB) production from domestic wastewater using Enterobacter aerogenes
12Bi strain. Afr J Microbiol Res 5(6):690-702. https://doi. org/10.5897/AJMR10.864

Poomipuk N, Reungsang A, Plangklang P (2014) Poly- $\beta$ hydroxyalkanoates production from cassava starch hydrolysate by Cupriavidus sp. KKU38. Int J Biol Macromol 65:51-64. https ://doi.org/10.1016/j.ijbiomac.2014.01.002

Prabisha TP, Sindhu R, Binod P, Sankar V, Raghu KG, Pandey A (2015) Production and characterization of PHB from a novel isolate Comamonas sp. from a dairy effluent sample and its application in cell culture. Biochem Eng J 101:150-159

Ram Kumar PS, Deepak V, Kalishwaralal K, Rameshkumar N, Jeyaraj M, Gurunathan S (2010) Optimization and fed-batch production of PHB utilizing dairy waste and sea water as nutrient sources by Bacillus megaterium SRKP-3. Bioresour Technol 101:705-711

Shivakumar S (2012) Polyhydroxybutyrate (PHB) production using agro-industrial residue as substrate by Bacillus thuringiensis IAM 12077. Int J ChemTech Res 4(3):1158-1162

Verlinden RA, Hill DJ, Kenward MA, Williams CD, Piotrowska-Seget Z, Radecka IK (2011) Production of polyhydroxyalkanoates from waste frying oil by Cupriavidus necator. AMB Express 1(1):11. https://doi.org/10.1186/2191-0855-1-11

Yamada-Onodera K, Mukumoto H, Katsuyaya Y, Saiganji A, Tani Y (2001) Degradation of polyethylene by a fungus Penicillium simplicissimum YK. Polym Degrad Stab 72:323-327

Yoshida S, Hiraga K, Takehana T, Taniguchi I, Yamaji H, Maeda Y, Toyohara K, Miyamoto K, Kimura Y, Oda K (2016) A bacterium that degrades and assimilates poly (ethylene terephthalate). Science 351:1196-1199

Publisher's Note Springer Nature remains neutral with regard to jurisdictional claims in published maps and institutional affiliations. 